\title{
ОСОБЕННОСТИ ПОВЕДЕНИЯ ИЗОТОПОВ ГЕЛИЯ В МИНЕРАЛАХ ГРУППЫ АМФИБОЛА ИЗ МАССИВА БЕЛЫЕ ТУНДРЫ, ВЫЯВЛЕННЫЕ ПРИ ИХ ЛАБОРАТОРНОМ ИЗУЧЕНИИ ДЕСТРУКТИВНЫМИ МЕТОДАМИ
}

\section{Каменский И.Л., Скиба В И., Ганнибал М.А., Гудков А.В.}

Геологический институт КНЦ РАН, Anamumbl, iglkam@mail.ru

Более 40 лет тому назад Ю.Д. Пушкарев, разбираясь в причинах нереально высоких значений К-Аг возраста, сравнивал кривые выхода аргона при плавном подъеме температуры (аргонограммы) для навесок минерала с разной крупностью частиц (зерна и пудра) [1]. Это позволило ему выявлять аргон в составе флюидных включений, т.е. аргон захваченный, а не наработанный «in situ» из ${ }^{40} \mathrm{~K}$. Этот захваченный аргон и завышал реальный возраст. Он снимал аналогичные кривые и для гелия (гелиограммы) для зёрен минерала и пудры из него. Аргон и гелий, которые проявляли себя на кривых выхода при изучении зерен, но отсутствовали при изучении пудры, он назвал аргон/гелий «пузырьковой формы», имея в виду, что эти газы содержатся в газово-жидких включениях.

Этот приём (когда из образца приготавливаются навески с разной крупностью зерен и, после анализов каждой, результаты сопоставляются) активно используется и сейчас. Причем не только в модификации линейного нагрева (снятие гелио- и аргонограмм), но и в форме ступенчатого нагрева, при котором определяется и содержание, и изотопный состав $\mathrm{He}$ и $\mathrm{Ar}$, выделившихся на каждой температурной ступени. [2, 3, 4]. Во всех этих работах гелий, который проявлял себя при изучении зерен (флюидные включения внутри зерен заставляли эти зерна растрескиваться только при достижении определенной, иногда очень высокой, температуры), в пудре уже отсутствовал (при истирании зерен в пудру флюидные включения разрушались на стадии подготовки навесок). При сопоставлении гелиограмм или графиков ступенчатого нагрева для зерен и пудры (желательно близких по массе навесок) это отсутствие очень заметно.

Для образцов, результаты по которым обсуждались в вышеперечисленных работах, использовалось и дробление в вакууме зерен этих образцов, при этом флюидные включения разрушались, а гелий/аргон в их составе исследовался как на содержание, так и на изотопный состав.

При интерпретации данных, полученных при таких разных способах воздействия на минералы, удавалось выявить разные места нахождения гелия/аргона в каждом конкретном образце и, с учетом данных по родительским элементам (U, Th, Li, K), разбраковать их по происхождению.

При изучении амфибола (рибекит) из кварц-полевошпатовой жилы Понойского массива [5], из которой ранее был разносторонне исследован ильменит [3], сопоставление гелиограмм для зерен и пудры свидетельствовало о высоком содержании гелия в «пузырьковой форме», однако дробление, при котором пузырьки вскрываются механически, позволило высвободить только 3 \% гелия от его общего количества. Исследование этого противоречия привело к выводу, что причиной растрескивания зерен при термическом воздействии является не флюидные включения, а твердофазные включения рутила; этот минерал характеризуется другим коэффициентом теплового расширения относительно амфибола, что и провоцирует растрескивание (наличие спайности у амфибола этому способствует).

Ниже представлены результаты по двум новым образцам амфиболов из массива щелочных гранитов Белые Тундры. Образец 5/с был выделен/выбран из керна скважины с глубины 5 м. Образец 11-7/16 отобран на поверхности, амфибол - вкрапления в кварцевой жиле. В таблице 1 представлены данные о содержании и изотопном составе при дроблении (гелий флюидных включений) и при плавлении (суммарный гелий - наработанный « in situ» и захваченный).

Таблица 1. Результаты изотопного анализа гелия в амфиболе из массива Белые тундры.

\begin{tabular}{|c|c|c|c|c|c|}
\hline Образец & фракция, мм & навеска, $\Gamma$ & ${ }^{4} \mathrm{He} \times 10^{-6} \cdot \mathrm{cm}^{3} / \Gamma$ & ${ }^{3} \mathrm{He} /{ }^{4} \mathrm{He} \times 10^{-8}$ & метод экстракции \\
\hline $5 / \mathrm{c}$ & $-0.5+0.25$ & 0.088 & 980 & 25 & плавление \\
\hline $5 / \mathrm{c}$ & $-0.5+0.25$ & 0.340 & 30 & 46 & дробление \\
\hline $11-7 / 16$ & $-0.63+0.25$ & 0.4182 & 28.5 & 38 & дробление \\
\hline
\end{tabular}

Видно, что дробление освобождает очень малую долю гелия от его общего количества. На рисунке 1 б, г представлены гелиограммы зерен и пудры (в очередной раз реализована ме- 

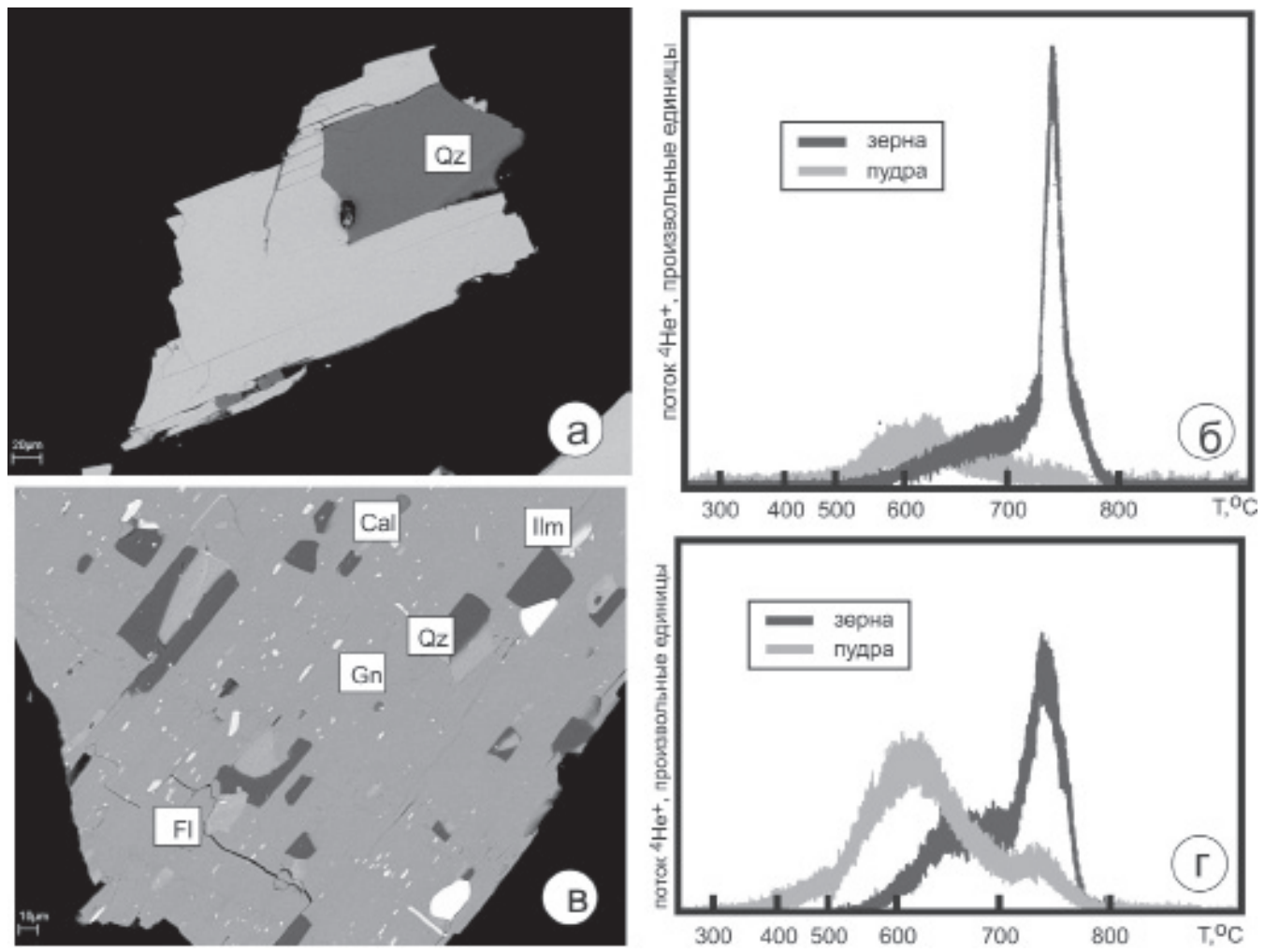

Рис. 1. (а, в) - микрофотографии образцов амфибола из массива Белые тундры (а) - обр. 11-7/16, отобран из кварц-полевошпатовой жилы; (в) обр 5/C, отобран из керна скважины. (б, г) кривые выхода гелия (гелиограммы) из образцов 11-7/16 и 5/С при постоянном подъеме температуры.

тодика Ю.Д. Пушкарева по выявлению «пузырьковой формы» гелия) и опять мы видим противоречие с результатами прямого извлечения Не дроблением. Повторяется ранее установленное явление[5], причиной которого опять стали твердофазные включения в этих образцах (рис. 1 а, в). В образце 5/с их очень много (рис. 1 в) и они разнообразны, а в другом мало и только кварц (рис. 1 а).

На гелиограмме для зерен обр 5/c (рис. 1 г) имеются две области выделения гелия: первая соответствует выделению гелия накопленного «in situ» в самом амфиболе. Про вторую область (острый пик) мы уже выяснили, что она не может быть обусловлена только с процессами, происходящими со структурой амфибола при нагревании, иными словами этот пик должен соответствовать какому-то месту нахождения гелия. Эта область также не соответствует разрушению флюидных включений, поскольку дроблением установлено их (почти) полное отсутствие. В случае образца 5/С этот гелий мог бы содержаться в многочисленных и разнообразных твердофазных включений, имеющихся в образце. Однако в образце 11-7/16 (рис. 1 б) такие включения практически отсутствуют, тем не менее, кривая выхода гелия имеет схожую форму, «острый» пик хорошо выражен. Причина возникновения этого пика, таким образом, пока не ясна.

Работа выполнена в рамках темы НИР ГИ КНЦ РАН № 0231-2015-0012.

\section{Литература}

1. Актуальные проблемы K-Ar геохронологии / Пушкарев Ю.Д. Апатиты: Изд-во КФАН. 1977. 53 С.

2. Каменский И.Л., Скиба В.И. Определение генезиса декрепитирующих и недекрепитирующих микровключений в минералах горных пород путем изучения изотопов гелия и аргона // Геохимия. 2011. №.1. С. 50-59.

3. Толстихин И.Н., Скиба В.И., Севостьянов А.Ю., Каменский И.Л., Ветрин В.Р. Места нахождения и происхождение благородных газов в минералах (на примере ильменита из щелочных гранитов Кольского полуострова). Геохимия. № 12. 2014. С. 1099-1107.

4. Tolstikhin I., Kamensky I.L., Tarakanov S., Kramers J., Pekala M., Skiba V., Gannibal M., Novikov D. Noble gas isotope sites and mobility in mafic rocks and olivine. Geochim. Cosmochim. 2010. A. 74, P. 1436-1447.

5. Tolstikhin I.N., Verchovsky A.B., Kamensky I.L., Skiba V.I., Gannibal M.A., Vetrin V.R. Amphibole: a major carrier of helium isotopes in crustal rocks // Chem. Geol. 2016. V. 444. P. 187-198. 